(C) American Dairy Science Association, 2005.

\title{
Letter to the Editor: Vaccenic and Rumenic Acids, A Distinct Feature of Ruminant Fats*
}

\author{
F. Destaillats, E. Buyukpamukcu, P.-A. Golay, F. Dionisi, and F. Giuffrida \\ Nestlé Research Center, Quality and Safety Department, Lausanne, Switzerland
}

The letter of Ellen and Elgersma (2004) on the use of the term "n-7 fatty acids" in place of cis-9, trans-11 18:2 and trans-11 18:1 acids, or their trivial names rumenic acid and vaccenic acid is an excellent opportunity to review both the origin of vaccenic and rumenic acids and their nomenclature. The name "vaccenic acid" was derived from the Latin vacca (cow), and this fatty acid was discovered in 1928 in animal fats and butter (Bertram, 1928). Vaccenic acid is the main trans fatty acid isomer present in milk fat, and it is formed with conjugated linoleic acid (CLA, cis-9, trans-11 18:2 acid) by biohydrogenation of dietary polyunsaturated fatty acids in the rumen (Bauman and Griinari, 2003). It was shown that mammals could partially convert vaccenic acid into cis-9, trans-11 18:2 acid, a CLA isomer. Recently, the name "rumenic acid" has been proposed as a common name for this naturally occurring CLA isomer (Kramer et al., 1998).

Ellen and Elgersma (2004) proposed to use "n-7 fatty acids" for both vaccenic and rumenic acid instead of CLA or trans fatty acids. In the biochemical nomenclature, the position of the terminal double bond can be denoted in the form (n-x), where $\mathrm{n}$ is the length of the fatty acid chain and $x$ is the number of carbon atoms from the last double bond, assuming that all the other double bonds are methylene-interrupted (Gunstone et al., 1994). Therefore, the use of both $n-x$ and omega-x terminologies are restricted to monoenoic and polyunsaturated fatty acids having methylene-interrupted ethylenic double bonds. Moreover, the n-7 fatty acid

Received October 29, 2004.

Accepted October 29, 2004.

Corresponding author: Frédéric Destaillats; e-mail: frederic. destaillats@rdls.nestle.com.

*Comment on the letter of Ellen and Elgersma entitled "Plea for using the term n-7 fatty acids in place of C18:2 cis-9,trans-11, and C18:1 trans-11 or their trivial names rumenic acid and vaccenic acid rather than the generic term conjugated linoleic acids" [J. Dairy Sci. 87:1131]. family consists of the metabolites formed from palmitoleic (16:1 n-7) acid (Wolff, 1995).

The arguments of the authors to exclude vaccenic and rumenic acid from the trans fatty acid and the CLA categories, respectively, are based on the nutritional values of these lipids. However, in the strictest sense, vaccenic and rumenic acids should be considered trans and conjugated fatty acids, respectively. It is well established that these two components have specific metabolic behaviors. In particular, due to future mandatory labeling of trans fatty acids in food products, the assessment of cardiovascular heart disease risk of vaccenic acid compared with elaidic acid should be considered a priority for the dairy science community (Aro, 2004).

In conclusion, the idea of Ellen and Elgersma (2004) to distinguish trans-11 18:1 and cis-9, trans-11 18:2 acids from the other trans and conjugated fatty acids formed by processing oils and fats is acceptable. However, for the reasons discussed above, the use of $n-7$ terminology is not suitable. In our opinion, it is much more appropriate to use their trivial names, vaccenic and rumenic acids.

\section{REFERENCES}

Aro, A. 2004. TFA isomers and the missing evidence. Eur. J. Lipid Sci. Technol. 106:345-346.

Bauman, D., and J. M. Griinari. 2003. Nutritional regulation of milk fat synthesis. Annu. Rev. Nutr. 23:203-227.

Bertram, S. H. 1928. Die Vaccensäure. (Eine neue Fettsäure aus Rinder-, Schafs- und Butterfet). Biochem. Z. 197:433-441.

Ellen, G., and A. Elgersma. 2004. Letter to the Editor: Plea for using the term n-7 fatty acids in place of $\mathrm{C} 18: 2$ cis-9, trans- 11 , and C18:1 trans-11 or their trivial names rumenic acid and vaccenic acid rather than the generic term conjugated linoleic acids. J. Dairy Sci. 87:1131.

Gunstone, F. D., J. L. Harwood, and F. B. Padley. 1994. The Lipid Handbook. 2nd ed. Chapman \& Hall, London, UK.

Kramer, J. K. G., P. W. Parodi, R. G. Jensen, M. M. Mossoba, M. P. Yurawecz, and R. O. Adlof. 1998. Rumenic acid: A proposed common name for the major conjugated linoleic acid isomer found in natural products. Lipids 33:835.

Wolff, R. L. 1995. Recent applications of capillary gas-liquid chromatography to some difficult separations of positional or geometrical isomers of unsaturated fatty acids. Pages 147-180 in New Trends in Lipid and Lipoprotein Analyses. J.-L. Sébédio and E. G. Perkins, ed. AOCS Press, Champaign, IL. 